ORIGINAL ARTICLE

\title{
Determination of flexibility and mobility levels for female physical education students and motor asymmetry analysis
}

\author{
Milaim Berisha ${ }^{\mathrm{ABCDE}}$ \\ School of Physical Education and Sport, Istanbul Gelisim University, Turkey
}

Authors' Contribution: A - Study design; B - Data collection; C - Statistical analysis; D - Manuscript Preparation; E - Funds Collection.

\begin{tabular}{|c|c|}
\hline \multicolumn{2}{|l|}{ Abstract } \\
\hline $\begin{array}{l}\text { Background } \\
\text { and Study Aim }\end{array}$ & $\begin{array}{l}\text { The aim of the study is the determination of flexibility and mobility levels (norm values) for female physical } \\
\text { education students and analyses of the motor asymmetry. }\end{array}$ \\
\hline $\begin{array}{l}\text { Material and } \\
\text { Methods }\end{array}$ & $\begin{array}{l}\text { In the study, } 10 \text { female physical education and sport students whose mean body weight was } 59.3 \mathrm{~kg} \text { and } \\
\text { body height were } 167.7 \text { centimeters were included. Flexibility and mobility performance was measured } \\
\text { by using tests such as a Forward-Backward Split }\left(\mathrm{FBS}^{\circ}\right) \text {, Leg Raise forward }\left(\mathrm{LRF}^{0}\right) \text {, Leg Raise Sideward }\left(\mathrm{LRS}^{\circ}\right) \text {, } \\
\text { Side Spit }\left(\mathrm{SS}^{0}\right) \text {, Arm-Trunk Angle }\left(\mathrm{AT}^{0}\right) \text {, Seat and reach hip angle degree }\left(\mathrm{SRHA}^{0}\right) \text {. Data analysis in the study } \\
\text { was made by using the IBM SPSS statistics } 26 \text { program. To handle the results of the study, the Independent- } \\
\text { samples T-test and percentile(s) statistics were used. Norm values were given in four categories }\left(20^{\text {th }}, 40^{\text {th }} \text {, }\right. \\
\left.60^{\text {th }}, 80^{\text {th }}\right) \text { and middle fifty }\left(50^{\text {th }}\right) \text {. Calculation of the angle degrees was made by using the Kinovea-0.9.4-x64. } \\
\text { exe program. }\end{array}$ \\
\hline Results & $\begin{array}{l}\text { The findings have shown that the forward-backward split and leg raise forward angle degree when the } \\
\text { right leg was ahead is significantly higher (better flexibility) than the forward-backward split and leg raise } \\
\text { forward angle degree when the left leg was ahead }(p<0.05) \text {. However, differences in the leg raise sideward } \\
\text { angle degree in the right and left leg were not statistically significant }(p>0.05) \text {. }\end{array}$ \\
\hline Conclusions & $\begin{array}{l}\text { The study determined the level (norm values) of flexibility and mobility of female physical education } \\
\text { students. The right leg flexibility and mobility level resulted to be significantly higher in comparison to } \\
\text { the left leg. }\end{array}$ \\
\hline Keywords: & range of motion, functional skills, coaching, sport science students, norm values. \\
\hline
\end{tabular}

\section{Introduction}

The learning process in sport science is characterized by the demonstration of the elements by a coach, sports instructor, or teacher. Therefore, in the learning process in sports science, especially when technological tools are insufficient, practical teaching methods are also needed besides theoretical methods. Therefore, students should strengthen their motivation for independent motor activity [1-3]. The practical skills required for sports instructors may differ based on sport branches, exercise type, and needs of the sport's practitioners. All theoretical and practical skills are divided into different categories, and most of them can be learned in sport science institutions. In this respect, to raise the quality of the coaches, sports instructors, teacher, etc., it's in need to determine physical level required to guarantee success in the teaching process of each sport and exercises. Also, the individual level of every student's physical fitness should be taken into account when lesson programs are prepared [4-6].

Because the coaches do not execute movements with maximal effort when they teach athletes, a high level of power, speed, endurance, etc. may not be required. However, to demonstrate/imitate any element and show sequence, it may require an efficient level of range of motion (ROM), which is provided by flexibility (muscle's ability to stretch) and mobility (actively moving through a

(c) Milaim Berisha, 2021

doi:10.15561/20755279.2021.0503 range of motions) [7, 8]. Therefore, evaluation criteria of each lesson in physical education and sport science faculty should include needed physical preparation for being a coach. To clarify it, a certain percentage of the successful evaluation of students may be based on practical skills. For the physical education and sport students' full assessment, it is necessary to analyze the parameters of the functional condition of the body [9-11]. To provide a qualitative evaluation, firstly, the norm values must be determined for flexibility and mobility in sport science students. Heretofore, there is a lack of literature that determines the level (norm values which are supposed to be used in the evaluation process of students) of flexibility and mobility of sport science students. All these values can be found in the literature as norm values for the seat and reach test. This test is in use since 1988 as a part of EURO-FIT and some modified versions of seat and reach test [12-14], the test whose validity and reliability are debatable. Although the validity and reliability of the test are sufficient, flexibility and mobility of the body should be measured in more than one body joint $[15,16]$. The reliability and validity of the instruments used to measure flexibility and mobility are also debatable, and all these should be updated and replaced by new methods and instruments.

In the light of this information, the aim of the study is the determination of flexibility and mobility levels (norm values) for female physical education students and lateralization analysis. Besides this, the study aims to 
determine flexibility and mobility level in all main body joints by using new methods and instruments which can be seen in the methodology part.

\section{Material and Methods}

\section{Participants}

In the study, 10 female physical education and sport students whose mean body height was $59.3 \mathrm{~kg}$ and body height were 167.7 centimetres were included. The students included in the study and parents were informed about the benefits and risks (even there is no risk detected) of the study. The study was made according to the Helsinki Declaration which protects the privacy of the volunteers. The study was approved by the ethics committee of "Istanbul Gelisim University".

Tests included in the study.

Forward-Backward Split $\left(F B S^{0}\right)$ : The test's main aim is to measure the active flexibility of the lower limbs and hips muscles such as iliopsoas (psoas major, iliacus), quadriceps femoris group (rectus femoris, vastus lateralis, vastus medialis, sartorius), and hamstrings (biceps femoris, semitendinosus, semimembranosus etc.) [17]. The angle reference point was the hips (greater trochanter) and the angle line was put across the legs to the ankle (lateral malleolus). In exceptional situations (if the athlete's knee was not straight), the angle tool's reference point was the thigh plane to the knee. The test was applied on two sides: right leg forward position, and left leg forward position. Calculation of the angle degrees was made by using the Kinovea-0.9.4-x64.exe program. The results had recorded us a different variable for the left and right leg and the results were given in degrees $[15,16]$.

Leg Raise forward $\left(L R F^{0}\right)$ : The test's main aim is to measure the mobility (the ability of the athlete to apply movements from a wide-angle and in different directions as far as the joints allow) of the lower limbs flexor muscles such as an iliopsoas, pectineus, rectus femoris, sartorius, adductor longus, tensor fasciae latae, etc., [17]. The reference of the measurement, where the angle was based on, was the hips (greater trochanter). The angle line was put across the raised leg to the ankles (lateral malleolus) and the angle's other line was put across the upper body exactly on the vertical line on the coronal plane (frontal plane). Calculation of the angle degrees was made by using the Kinovea-0.9.4-x64.exe program. The results of the test were determined by the angle degree between raised leg and upper body $[15,16]$.

Leg Raise Sideward $\left(L R S^{0}\right)$ : The test's main aim is to measure the mobility (the ability of the athlete to apply movements from a wide-angle and in different directions as far as the joints allow) of the lower limbs abductor muscles such as gluteus medius, gluteus minimums, tensor fascia lata, gluteus maximus, etc. [17]. The reference of the measurement was the angle based on was the coccyx (tailbone). The angle line was put across the raised leg to the ankles (lateral malleolus) and the angle's other line was put across the upper body exactly on the vertical line on the sagittal plane. Calculation of the angle degrees was made by using the Kinovea-0.9.4-x64.exe program. The results of the test were determined by the angle degrees between raised leg and upper body $[15,16]$.

Side Spit $\left(S S^{0}\right)$ : The test's main aim is to measure the active flexibility of the lower limbs adductors such as pectineus, gracilis, adductor brevis, adductor longus, adductor magnus, etc. [16]. The angle reference point was the coccyx bone and the angle line was put across the legs to the ankle (lateral malleolus). Calculation of the angle degrees was made by using the Kinovea-0.9.4-x64.exe program. The results were given in degrees $[15,16]$.

Arm-Trunk Angle $\left(A T^{0}\right)$ : The test's main aim is to measure the active flexibility and mobility of the shoulders and upper limbs muscles such as triceps brachii, posterior deltoid, teres minor, teres major, latissimus dorsi pectorals abdominal and sternocostal part, etc. [17]. The angle reference point was the upper limit of middle axillary line (biacromial elevation level) and the angle line was put across the hand joint (styloid process of ulna) and hips (greater trochanter). Calculation of the angle degrees was made by using the Kinovea0.9.4-x64.exe program. The results had recorded us an angle given between the trunk and raised arms [15, 16]. The test was applied in two body planes which are evaluated as different variables: ATA $^{0}$ SHF: Arm-Trunk Angle (shoulder flexion), and ATA $^{0}$ SHE: Arm-Trunk Angle (shoulder extension).

Hip active flexibility (modified seat and reach test: seat and reach hip angle degree $S R H A^{\circ}$ )

Hip passive flexibility was measured by using the modified sit and reach test. The test application was made by following the instructions of the seat reach test $[13,14]$. Instead of using the seat and reach the box, measurements were made by using Kinovea-0.9.4-x64.exe program (Kinovea, 2021). Instead of measuring the reach distance, during the test hip angle degree was measured (as the center of angle were determined greater trochanter, firstline were from greater trochanter to acromion and second line from the greater trochanter to the lateral epicondyle of the femur), and clinical hip angle degree (as the center of the angle, lumbar spine, the first line of angle starts from lumbar spine (L5) across the lumbar spine (L1) to thoracic spine, and second-line starts from the lumbar spine (L5) to the lateral epicondyle of the femur were determined) [17].

\section{Statistical analysis}

Data analysis in the study was made by using the IBM SPSS statistics 26 program. The normality of the data was tested by the skewness and kurtosis analysis. Based on the normality of the data, differences between two independent variables were calculated by using the Independent-samples T-test analysis. Determination of the level (norm values) of flexibility and mobility, and percentile(s) statistics were used. Norm values were given in four categories $\left(20^{\text {th }}, 40^{\text {th }}, 60^{\text {th }}, 80^{\text {th }}\right)$ and middle fifty $\left(50^{\text {th }}\right)$. 


\section{Results}

The findings given in Table 1 show that the FBS angle degree when the right leg was ahead was significantly higher (better flexibility) than the FBS angle degree when the left leg was ahead $(\mathrm{p}<0.05)$. In addition, the LRF angle degree resulted to be significantly lower in the right leg in comparison to the left leg $(\mathrm{p}<0.05)$, which means better flexibility and mobility expressed in the right leg. Differences in LRS angle degree in the right and left leg were not statistically significant $(\mathrm{p}>0.05)$, nevertheless the angle degree average of the right leg was lower than the average of the left leg, which means that flexibility and mobility of the right leg are higher in comparison to the left leg.

As figures 1-4 show, table 2 determines the level (norm values) of $\mathrm{FBS}^{0}$ and $\mathrm{LRF}^{0}$ for the right and left leg. Norm values were given in four categories (20th, 40th, 60th, 80th) and middle fifty (50th). Based on the skewness and kurtosis values, all variables seem to be normal (mesocortical).

Figures 1-4 represent the flexibility and mobility levels

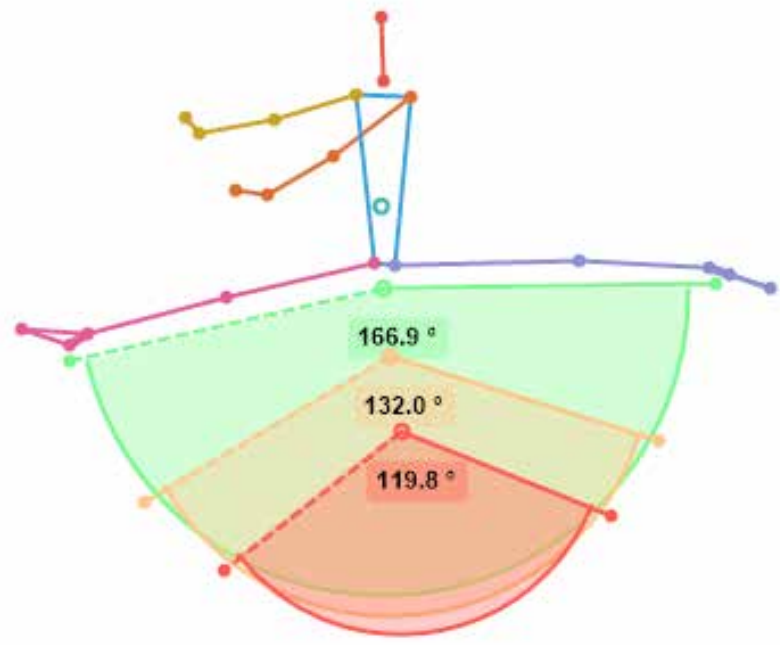

Figure 1. Min., Max., and Middle fifty of FBS-RL test

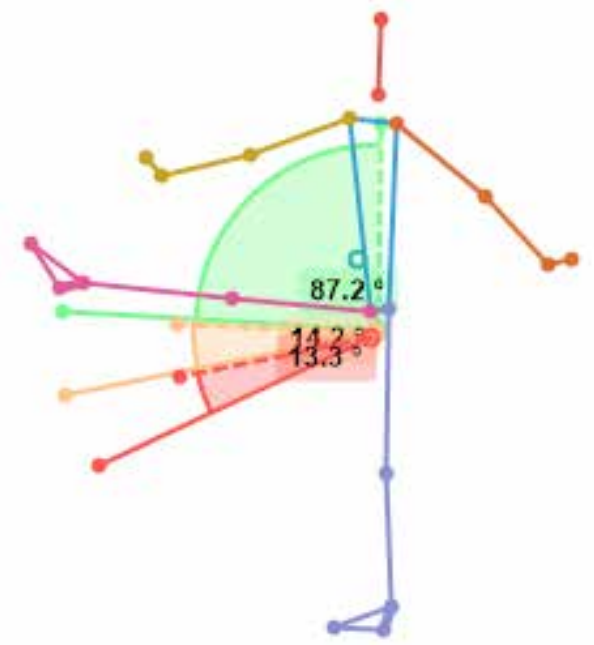

Figure 3. Min., Max., and Middle fifty of LRF-RL test of female physical education and sport science students, where the asymmetry level is determined based on data in table 2 .

As figures 5-7 show, table 3 determines the level (norm values) of SS, and $\mathrm{LRS}^{0}$ for the right and left leg. Norm values were given in four categories (20th, 40th, 60th, 80th) and middle fifty (50th). Based on the skewness and kurtosis values, all variables seem to be normal (mesocortical).

Figures 5-7 represent the flexibility and mobility levels of female physical education and sport students, where the asymmetry level is determined based on data in table 3 . In addition, the SS test (figure 5) helps to compare differences between flexibility and mobility levels in the same muscle group (differences in SS and LRS tests).

As figures 8-10 show, table 4 determines the level (norm values) of $\mathrm{AT}^{0}$ (arm-trunk angle in shoulder flexion and extension), and SRT measured in centimeters (SRT), and as the angle degree of the hips $\left(\mathrm{SRHA}^{0}\right)$. Norm values were given in four categories (20th, 40th, 60th, 80 th) and middle fifty (50th). Based on the skewness

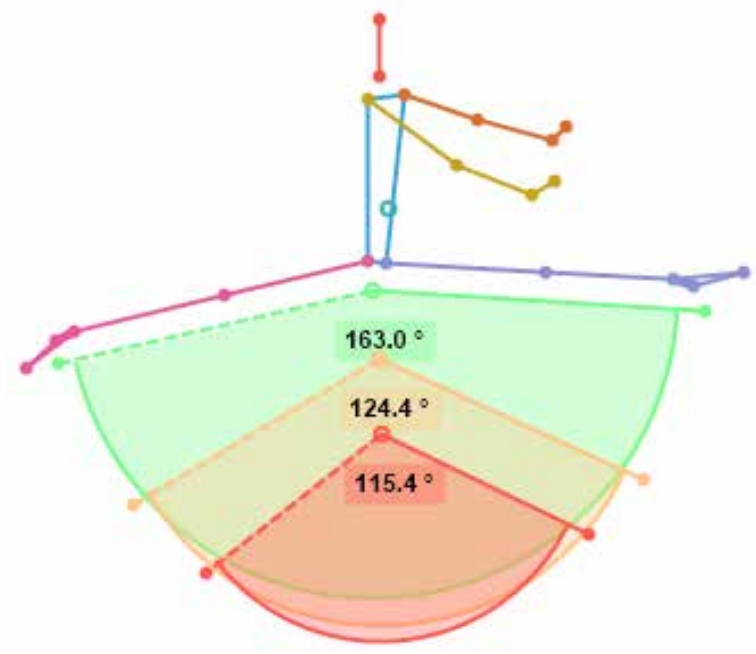

Figure 2. Min., Max., and Middle fifty of FBS-LL test

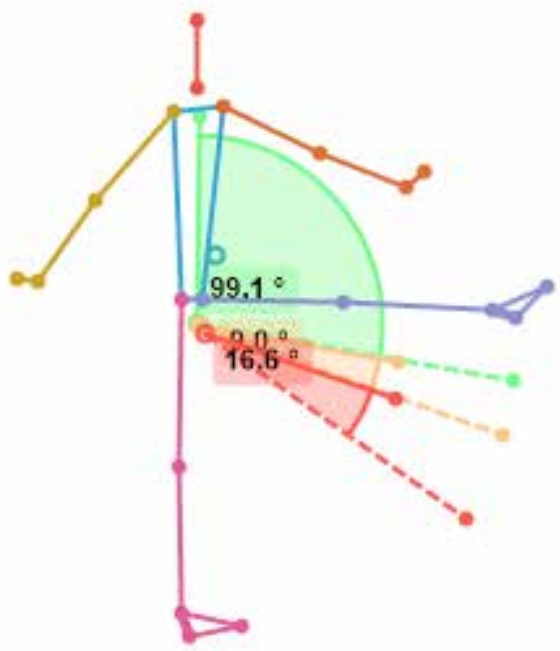

Figure 4. Min., Max., and Middle fifty of LRF-LL test 
Table 1. Flexibility and mobility asymmetry level of the forward-backward split, leg raise forward, leg raise sideward

\begin{tabular}{llll}
\hline Variables & & $\overline{\mathbf{X}} \pm$ SD & $\mathbf{p}$ \\
\hline \multirow{2}{*}{ FBS } & FBS-RL & $139.9 \pm 20.2$ & $.007^{*}$ \\
& FBS-LL & $132.9 \pm 21.7$ & \\
\multirow{2}{*}{ LRF } & LRF-RL & $100.7 \pm 12.0$ & $.001^{*}$ \\
& LRF-LL & $109.7 \pm 9.8$ & .277 \\
\hline \multirow{2}{*}{ LRS } & LRS-RL & $104.2 \pm 9.8$ & \\
& LRS-LL & $108.0 \pm 14.0$ & \\
\hline
\end{tabular}

P<0.05*; FBS: Forward-Backward Split, LRF: Leg Raise forward, LRS: Leg Raise Sideward, FBS-RL: Forward-Backward Split (Right Leg), FBS-LL: Forward-Backward Split (Left Leg), LRF-RL: Leg Raise Forward (Right Leg), LRF-LL: LRS-RL: Leg Raise Sideward (Right Leg), LRS-LL: Leg Raise Sideward (Left Leg)

Table 2. Flexibility and mobility level (norm values) of the forward-backward split, leg raise forward

\begin{tabular}{|c|c|c|c|c|c|}
\hline & & \multicolumn{2}{|l|}{ FBS $^{0}$} & \multicolumn{2}{|l|}{ LRF $^{0}$} \\
\hline & & FBS-RL & FBS-LL & LRF-RL & LRF-LL \\
\hline \multicolumn{2}{|c|}{$\overline{\mathrm{X}} \pm S D$} & $139.9 \pm 20.2$ & $132.9 \pm 21.7$ & $100.7 \pm 12.0$ & $109.7 \pm 9.8$ \\
\hline \multicolumn{2}{|c|}{ Skew. } & .495 & .829 & .018 & .649 \\
\hline \multicolumn{2}{|l|}{ Kur. } & -1.297 & -.786 & -1.970 & -.709 \\
\hline \multicolumn{2}{|c|}{ Range } & 53.6 & 57.7 & 28.8 & 26.9 \\
\hline \multirow{5}{*}{ 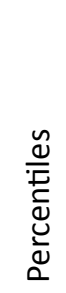 } & $20^{\text {th }}$ & 119.1 & 115.8 & 87.3 & 99.5 \\
\hline & $40^{\text {th }}$ & 130.7 & 118.0 & 93.2 & 104.9 \\
\hline & $50^{\text {th } *}$ & 132.0 & 124.2 & 101.4 & 107.1 \\
\hline & $60^{\text {th }}$ & 145.3 & 137.0 & 106.4 & 110.2 \\
\hline & $80^{\text {th }}$ & 166.7 & 163.1 & 114.1 & 123.4 \\
\hline
\end{tabular}

Skewness: > 1 - positive skew, \pm 0 - normal, <- 1 - negative skew; FBS ${ }^{0}$ Forward-Backward Split, LRF ${ }^{0}$ : Leg Raise forward, FBS-RL: Forward-Backward Split (Right Leg), FBS-LL: Forward-Backward Split (Left Leg), LRF-RL: Leg Raise Forward (Right Leg), LRF-LL: Leg Raise Forward (Left Leg), 50th*: middle fifty

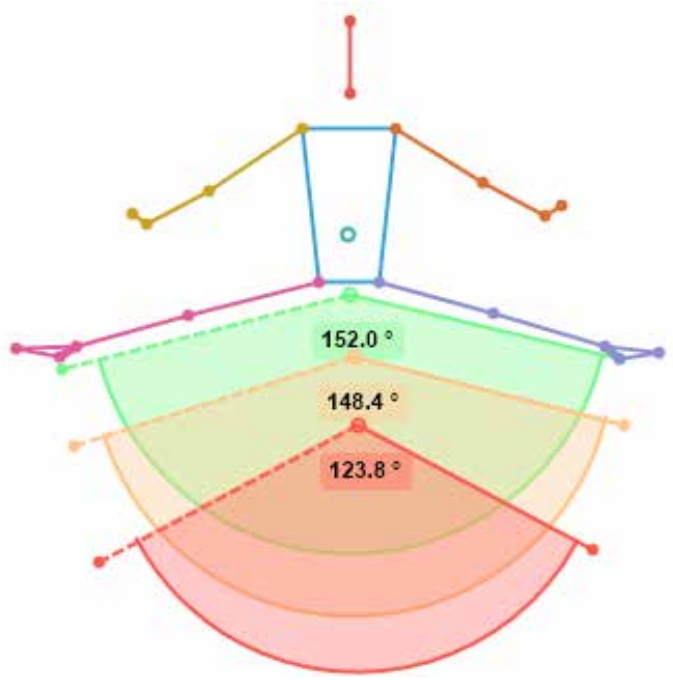

Figure 5. Min., Max., and Middle fifty of SS test

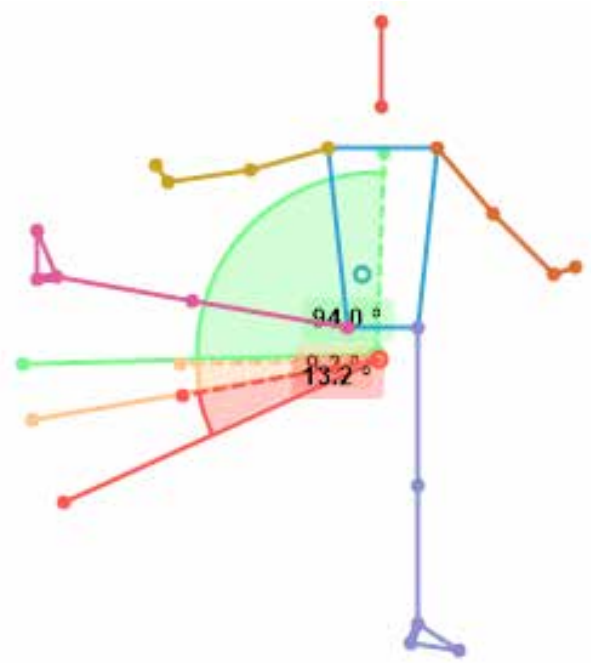

Figure 6. Min., Max., and Middle fifty of LRS-RL test 
Table 3. Flexibility and mobility level (norm values) of side split, leg raise sideward

\begin{tabular}{|c|c|c|c|c|}
\hline & & \multirow{2}{*}{ SS } & \multicolumn{2}{|l|}{ LRS $^{0}$} \\
\hline & & & LRS-RL & LRS-LL \\
\hline \multicolumn{2}{|c|}{$\bar{X} \pm S D$} & $139.2 \pm 12.25$ & $104.2 \pm 9.8$ & $108.0 \pm 14.0$ \\
\hline \multicolumn{2}{|c|}{ Skew. } & -.315 & .141 & -.675 \\
\hline \multicolumn{2}{|c|}{ Kur. } & -1.622 & -2.147 & -.645 \\
\hline \multicolumn{2}{|c|}{ Range } & 31.4 & 22.9 & 38.3 \\
\hline \multirow{5}{*}{ 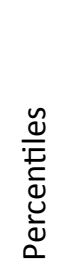 } & $20^{\text {th }}$ & 123.6 & 94.0 & 88.1 \\
\hline & $40^{\text {th }}$ & 134.3 & 96.3 & 110.2 \\
\hline & $50^{\text {th } *}$ & 143.0 & 103.4 & 110.7 \\
\hline & $60^{\text {th }}$ & 146.9 & 109.9 & 111.1 \\
\hline & $80^{\text {th }}$ & 152.3 & 116.0 & 123.1 \\
\hline
\end{tabular}

Skewness: > 1 - positive skew, \pm 0 - normal, < - 1 - negative skew; SS: Side Split, LRS ${ }^{0}:$ Leg Raise Sideward, LRS-RL: Leg

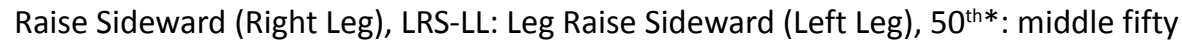

Table 4. Flexibility and mobility level (norm values) of arm-trunk angle, seat and reach test variations

\begin{tabular}{|c|c|c|c|c|c|}
\hline & & \multicolumn{2}{|l|}{$\mathbf{A T}^{0}$} & \multicolumn{2}{|l|}{ SRT } \\
\hline & & $\mathrm{ATA}^{0} \mathrm{SHF}$ & ATA $^{0}$ SHE & SRHA $^{0}$ & SRT cm \\
\hline \multicolumn{2}{|c|}{$\overline{\mathrm{X}} \pm \mathrm{SD}$} & $147.0 \pm 19.3$ & $117.8 \pm 10.5$ & $41.8 \pm 11.5$ & $13.9 \pm 7.1$ \\
\hline \multicolumn{2}{|c|}{ Skew. } & .695 & .036 & 1.240 & .205 \\
\hline \multicolumn{2}{|c|}{ Kur. } & -1.412 & -.113 & -.043 & -1.173 \\
\hline \multicolumn{2}{|c|}{ Range } & 49.7 & 38.1 & 29.2 & 20.9 \\
\hline \multirow{5}{*}{ 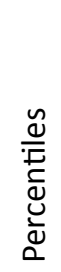 } & $20^{\text {th }}$ & 133.5 & 105.9 & 34.0 & 34.0 \\
\hline & $40^{\text {th }}$ & 135.8 & 115.6 & 34.6 & 34.6 \\
\hline & $50^{\text {th }} *$ & 136.2 & 117.4 & 34.9 & 34.9 \\
\hline & $60^{\text {th }}$ & 144.6 & 119.6 & 38.7 & 38.7 \\
\hline & $80^{\text {th }}$ & 173.8 & 128.1 & 59.2 & 59.2 \\
\hline
\end{tabular}

Skewness: > 1 - positive skew, \pm 0 - normal, < - 1 - negative skew; AT ${ }^{0}$ : Arm-Trunk Angle, ATA ${ }^{0}$ SHF: Arm-Trunk Angle (shoulder flexion), ATA ${ }^{\circ}$ SHE: Arm-Trunk Angle (shoulder extension), SRT: Seat and Reach Test, SRHA ${ }^{0}$ : Seat and reach Hip Angle Degree, 50th*: middle fifty

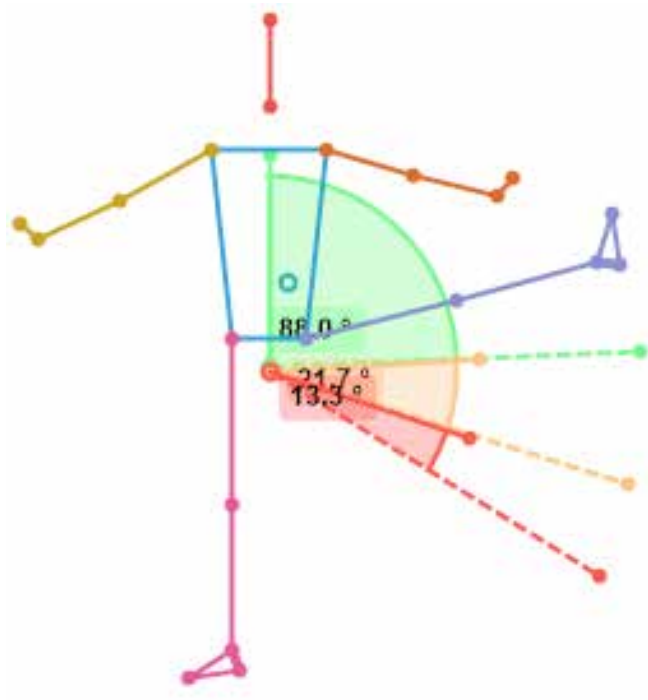

Figure 7. Min., Max., and Middle fifty of LRS-LL test

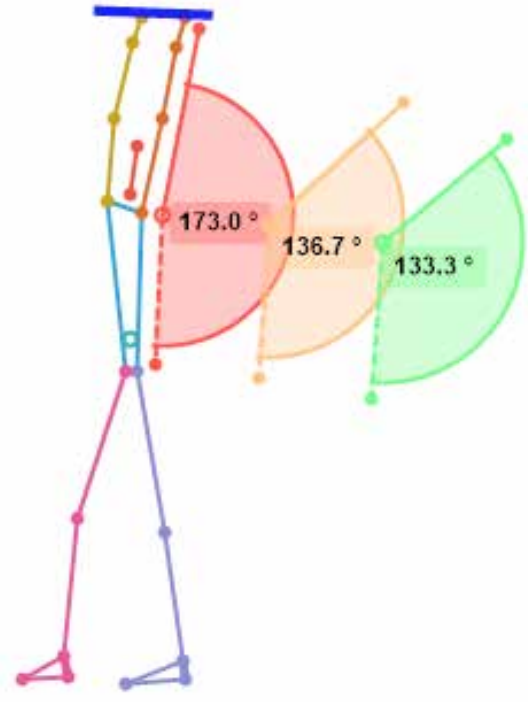

Figure 8. Min., Max., and Middle fifty of ATA ${ }^{0}$ SHF test 


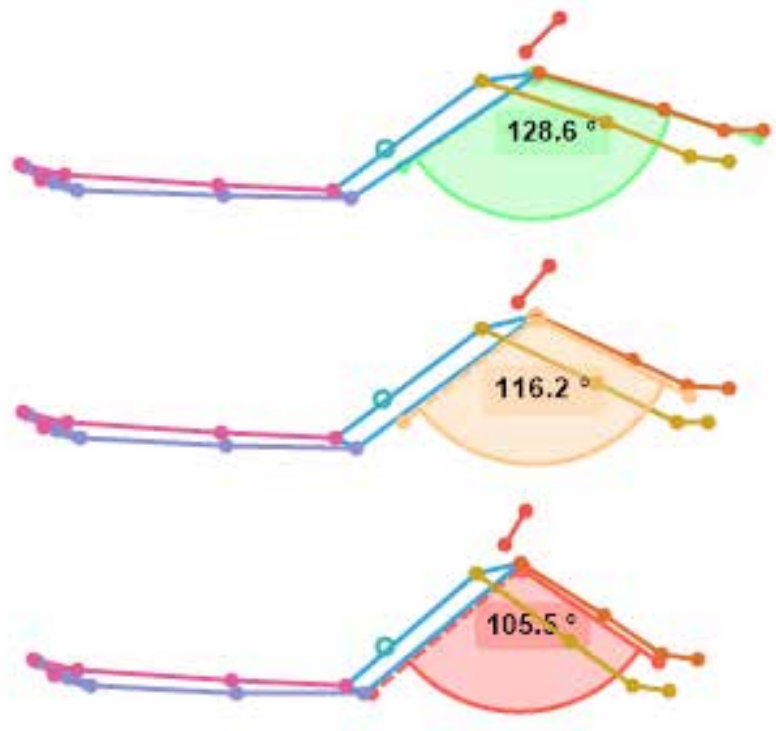

Figure 9. Min., Max., and Middle fifty of ATA ${ }^{0}$ SHE test

and kurtosis values, all variables seem to be normal (mesocortical)

In figures $8-10$, based on table 4 results minimal, maximal, and middle fifty of the ATA ${ }^{0} \mathrm{SHF}$, ATA ${ }^{0} \mathrm{SHE}$, and SRHA $^{0}$ tests were determined.

\section{Discussion}

In this study, the level (norm values) of flexibility and mobility were determined (see table 2-4) for female physical education students and the differences in flexibility and mobility were analyzed from a lateralization perspective (see table 1).

Based on the first table of the study, as can be seen in figures 1 and 2, the forward-backward angle degree when the right leg is ahead was significantly higher (better flexibility) than the forward-backward angle degree when the left leg was ahead. In addition, the figures 3 and 4 shows the leg raise forward angle degree resulted to be significantly lower in the right leg in comparison to the left leg, which means better flexibility and mobility expressed in the right leg. According to Yin et al., right hip torn out angle degree resulted to be higher $\left(60^{\circ}\right)$ compared to left hip torn out angle degree $\left(59^{\circ}\right)$ in adolescent ballet dancers. These differences seem to be significant in nontrained athletes [18]. According to the literature, the asymmetry levels are less in trained athletes compared to non-trained ones [19-22]. Therefore, improvements in flexibility and mobility may reduce the asymmetry levels in students. Literature showed that performance asymmetries can be altered by intense long-term practice [23]. On the other hand, differences in leg raise forward angle degree in the right and left leg were not statistically significant. Nevertheless, the angle degree average of the right leg was lower than the average of the left leg, which means that flexibility and mobility of the right leg were higher in comparison to the left leg.

In the light of the previous information, based on

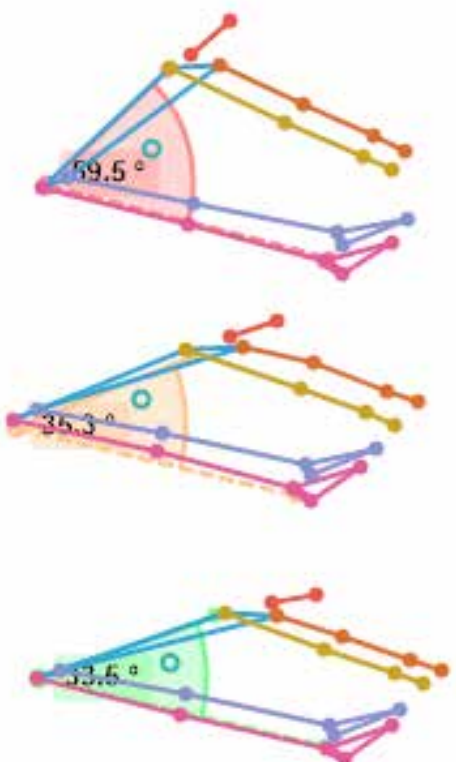

Figure 10. Min., Max., and Middle fifty of $\mathrm{SRHA}^{0}$ test

the current motor status of the participants, the levels (norm values) of flexibility and mobility of male physical education students were determined in tables 2-4. Based on the significant asymmetry, norm values were determined separately for right and leg hand and leg. The norm values were determined to measure flexibility and mobility $[8,24]$ in tests such as forward-backward split, leg raise forward, leg raise forward, leg raise sideward, side split, arm-trunk angle (shoulder flexion), arm-trunk angle (shoulder extension), sit and reach test, seat and reach hip angle degree $[8,15,16]$. To see more clearly asymmetry differences were given results in tables 2-4 and figures 1-10 where angle degrees simulations based on the table results of the study.

According to the literature, tests included in the study have no part of fitness, and functional tests are used to measure the performance level of physical education and sport students. Besides this, many studies seem to be focused on the wellness, and performance of the students, but not focused on the skills of the students which may improve their coaching performance [1, 9, 25-28]. Therefore, not the inclusion of the flexibility and mobility tests into test batteries can be considered as a missed point of selection tests to measure the performance of the physical education and sport science students.

According to the study results and literature, it can be concluded that flexibility and mobility play key roles in the learning process of the new elements in different sport such as gymnastics, dance, ballet, etc. For this reason, the independence of the coaches in motor activity may improve their coaching performance. In presenting the theoretical section of the subject "Physical Culture" to the students of the senior courses, it is necessary to strengthen their motivation for independent motor activity [1]. To do this is necessary to determine the physical and motor level $[29,30]$ of the population who are supposed to use the motor skills in the future job, as the physical education 
and sport science students are supposed to use practical skills in the coaching process.

\section{Conclusions}

As a conclusion, forward-backward angle degree when the right leg was ahead resulted to be significantly higher (better flexibility) than the forward-backward angle degree when the left leg was ahead. In addition, the leg raises forward angle degree resulted to be significantly lower in the right leg in comparison to the left leg, which means better flexibility and mobility expressed in the right leg.

According to the previous information, based on the current motor status of the participants, the levels (norm values) of flexibility and mobility of male physical education students were determined. Based on the significant asymmetry, norm values were also determined separately for right and leg hand and leg.

The literature investigation has shown that the flexibility and mobility tests (forward-backward split, leg raise forward, leg raise forward, leg raise sideward, side split, arm-trunk angle) are not included in the test batteries which are in use to measure the physical education and sport students' performance. Besides this, flexibility measurement is also based just on the seat reach test, and does not include all body joints where flexibility is expressed.

In the light of previous information, determination of norm values of flexibility and mobility by using tests such as a forward-backward split, leg raise forward, leg raises forward, leg raises sideward, side split, arm-trunk angle, may increase the independence in motor activity (techniques which require flexibility and mobility during execution) of coaches is a key factor to improve coaching performance in physical education and sport science students and the coaches of the future.

\section{Suggestions}

Determining the norm values for physical fitness based on the practical requirements of the coaching in certain sport branches.

Updating tests which are in use nowadays to measure and evaluate the performance of physical education and sport science students (coaches of the future). Besides this, updating the measurement tools in use and put in use a computer program, which can increase the reliability of the tests.

Studies on physical education and sport science students should be focused on the practical needs to increase coaching quality, instead of analyzing anthropometric and motoric parameters from a health and wellbeing perspective.

\section{Acknowledgements}

With pleasure, we thank the students listed below, who made possible this study by contributing on creating the study sample and data collection procedure: Aylin Nur KAR, Pelinsu ALTAY, Mertol BARUTÇU, Begüm ÜRK, Seher Gül, Sümeyye DEMIR, Muhammed NADİR, Ela DENİ, Melike UYSAL, Fatih KARACA.

\section{References}

1. DiBattistaR, RobazzaC, RuizMC, BertolloM,VitaliF, Bortoli L. Student intention to engage in leisure-time physical activity: The interplay of task-involving climate, competence need satisfaction and psychobiosocial states in physical education. European Physical Education Review. 2019;25(3):761-777. https://doi.org/10.1177/1356336x18770665

2. Johnson CE, Erwin HE, Kipp L, Beighle A. Student Perceived Motivational Climate, Enjoyment, and Physical Activity in Middle School Physical Education. Journal of Teaching in Physical Education. 2017;36(4):398-408. https://doi.org/10.1123/jtpe.2016-0172

3. Leyton-Roman $M$, Nunez JL, Jimenez-Castuera R. The Importance of Supporting Student Autonomy in Physical Education Classes to Improve Intention to Be Physically Active. Sustainability. 2020;12(10). https://doi.org/10.3390/su12104251

4. Lucas IR, Harris C, Lee S, Wargo J, Barnes SP, Kauh TJ, et al. Teacher Physical Education Practices and Student Outcomes in a Sample of Middle Schools Participating in the Presidential Youth Fitness Program. Preventing Chronic Disease. 2019;16. https://doi.org/10.5888/pcd16.180627

5. BlackshearTB,BartonAT, Moxley J.TheEvaluation of Student Fitness Levels in Exercise Science and Physical Education Teacher Education Programs. Quest. 2019;71(1):21-41. https://doi.org/10.1080/00336297.2018.1487309

6. Fredrick RN, Silverman S. Relationship between Urban Middle School Physical Education Teachers' Attitudes toward Fitness Testing and Student Performance on Fitness Tests. Measurement in Physical
Education and Exercise Science. 2020;24(4):273-281. https://doi.org/10.1080/1091367x.2020.1815024

7. Jeffreys I. Essentials of Strength Training and Conditioning. In: G Gregory Haff and N Travis Triplett (Editors) Warm-Up and Flexibility Training. National Strength and Conditioning Association NSCA. Human Kinetics; 2016. P.317-350.

8. Berisha M, Oktay G. A biomechanical examination of the differences between active flexibility and mobility in artistic gymnastics. VIREF Revista de Educación Física. 2021;3;10(2):145-55.

9. BoonekampGMM,DierxJAJ,JansenE.Motivatingstudentsfor physical activity: Whatcan we learn from student perspectives? European Physical Education Review. 2021;27(3):512-528. https://doi.org/10.1177/1356336x20970215

10.Foley BC, Shrewsbury VA, Hardy LL, Flood VM, Byth K, Shah S. Evaluation of a peer education program on student leaders' energybalance-related behaviors. BmcPublicHealth.2017;17. https://doi.org/10.1186/s12889-017-4707-8

11.Stolarska B, Stolarski M, Matthews G. A Comparison of the Effects of 45-minute Aerobic Training and Cognitive Task Solving on Transient Mood States in a Female Student Sample. Applied PsychologyHealth and Well Being. 2019;11(3):499-521. https://doi.org/10.1111/aphw.12165

12.Wiśniowska-Szurlej A, Ćwirlej-Sozańska A, Wołoszyn N, Sozański B, Wilmowska-Pietruszyńska A. Association between handgrip strength, mobility, leg strength, flexibility, and postural balance in older adults under long-term care facilities. BioMed Research International, 2019;23;2019. https://doi.org/10.1155/2019/1042834 
13. Council of Europe. Sport Testing Physical Fitness Experimental Battery. Strasbourg; 1983.

14.Council of Europe. Recommendation no. $R$ (87) of the Commitee of Ministers to Member States on the Eurofit Tests of Physical Education. 1987.

15.Fink H, Hofmann D, López L.O. Age Group Development and Competition Program for Women's Artistic Gymnastics. Fédération Internationale De Gymnastique (FIG); 2015.

16.Fink H, Hofmann D. Age Group Development and Competition Program for Men's Artistic Gymnastics. Fédération Internationale De Gymnastique (FIG); 2015.

17.Süzen L.B. Movement system anatomy and kinesiology. Istanbul: Nobel Medical Bookstores; 2017. (In Turkish).

18. YinA.X, GeminianiE, Quinn B, Owen M, Kinney S, McCrystal T, Stracciolini A. The evaluation of strength, flexibility, and functional performance in the adolescent ballet dancer during intensive dance training. Pm\&r. 2019;11(7):722-30. https://doi.org/10.1002/pmrj.12011

19.Kalata M, Maly T, Hank M, Michalek J, Bujnovsky D, Kunzmann E, et al. Unilateral and Bilateral Strength Asymmetry among Young Elite Athletes of Various Sports. Medicina-Lithuania. 2020;56(12). https://doi.org/10.3390/medicina56120683

20.Mattes K, Wollesen B, Manzer S. Asymmetries of maximum trunk, hand, and leg strength in comparison to volleyball and fitness athletes. Journal of Strength and Conditioning Research. 2018;32(1):57-65. https://doi.org/10.1519/JSC.0000000000002183

21.Morishige Y, Harato K, Kobayashi S, Niki Y, Matsumoto $M$, Nakamura $M$, et al. Difference in leg asymmetry between female collegiate athletes and recreational athletes during drop vertical jump. Journal of Orthopaedic Surgery and Research. 2019;14(1). https://doi.org/10.1186/s13018-019-1490-5

22.Teixeira RV, de Queiros VS, Dantas MP, Assis MG, Dantas PMS, Cabral B. Asymmetry inter-limb and performance in amateur athletes involved in high intensity functional training. Isokinetics and Exercise Science. 2020;28(1):83-89. https://doi.org/10.3233/ies-194201
23.Akpinar S, Sainburg R.L, Kirazci S, Przybyla A. Motor asymmetry in elite fencers. Journal of Motor Behavior. 2015;47(4):302-11. https://doi.org/10.1080/00222895.2014.981500

24.Berisha M. Normative values for physical and psychomotor characteristics in children aged 4-7 in Turkey (Sakarya). Human. Sport. Medicine. 2021;21(1):94-101.

25.Fredrick RN, Silverman S. Relationship between Urban Middle School Physical Education Teachers' Attitudes toward Fitness Testing and Student Performance on Fitness Tests. Measurement in Physical Education and Exercise Science. 2020;24(4):273-281. https://doi.org/10.1080/1091367x.2020.1815024

26. Araujo RMF, Hastie PA, Pereira C, Mesquita IMR. The evolution of student-coach's pedagogical content knowledge in a combined use of sport education and the step-game-approach model. Physical Education and Sport Pedagogy. 2017;22(5):518-535. https://doi.org/10.1080/17408989.2017.1294668

27.Farias C, Valerio C, Mesquita I. Sport Education as a Curriculum Approach to Student Learning of Invasion Games: Effects on Game Performance and Game Involvement. Journal of Sports Science and Medicine. 2018;17(1):56-65.

28.Mateu $\mathrm{P}$, Ingles $\mathrm{E}$, Torregrossa $\mathrm{M}$, Marques RFR, Stambulova N, Vilanova A. Living Life Through Sport: The Transition of Elite Spanish StudentAthletes to a University Degree in Physical Activity and Sports Sciences. Frontiers in Psychology. 2020;11. https://doi.org/10.3389/fpsyg.2020.01367

29.Catley MJ, Tomkinson GR. Normative health-related fitness values for children: analysis of 85347 test results on 9-17-year-old Australians since 1985. British Journal of Sports Medicine, 2013;47(2):98-108. https://doi.org/10.1136/bjsports-2011-090218

30.Berisha M, Cilli M. Physical Fitness Norms in Student aged 8-17 in Kosovo. Latvia: LAP LAMBERT Academic Publishing; 2018.

\section{Information about the author:}

Milaim Berisha; https://orcid.org/0000-0002-0353-7247; dr.milaimberisha@gmail.com; Coaching Department, School of Physical Education and Sport, Istanbul Gelisim University; Istanbul, Turkey.

\section{Cite this article as:}

Berisha M. Determination of flexibility and mobility levels for female physical education students and motor asymmetry analysis. Physical Education of Students, 2021;25(5):272-279.

https://doi.org/10.15561/20755279.2021.0503

This is an Open Access article distributed under the terms of the Creative Commons Attribution License, which permits unrestricted use, distribution, and reproduction in any medium, provided the original work is properly cited http://creativecommons.org/licenses/by/4.0/deed.en

Received: 03.09.2021

Accepted: 06.10.2021; Published: 30.10 .2021 